\title{
PENGARUH PENGETAHUAN MENGENAI ISU-ISU LINGKUNGAN (KNOWLEDGE ABOUT ENVIRONMENTAL ISSUES) DAN INTENSI UNTUK BERTINDAK (INTENTION TO $A C T)$ TERHADAP PERILAKU BERTANGGUNG JAWAB LINGKUNGAN (RESPONSIBLE ENVIRONMENTAL BEHAVIOR) SISWA
}

\author{
Fibula Purnama $^{1}$, I Made Putrawan ${ }^{2}$, Diana Vivanti Sigit ${ }^{3}$ \\ ${ }^{1}$ Student of Biology Education Departement of State University of Jakarta \\ ${ }^{2}$ Environmental Education Departement of State University of Jakarta \\ ${ }^{3}$ Biology Education Departement of State University of Jakarta
}

\author{
Email: fibulapurnama13@gmail.com \\ putrawan.imade@yahoo.com \\ dianavivanti@yahoo.com
}

\begin{abstract}
Environmental issues is the problem that need to be solved by all parties, including students, by developing responsible of environmental issues. Students' responsible environmental behavior is an output that came from factors that have effects toward it. Some of the effects are knowledge about environmental issues and intention to act. This study aims to determine the effect of knowledge about environmental issues and intention to act toward responsible environmental behavior that student have. This research conducted at SMAN 4 Kota Bekasi on the $1^{\text {st }}$ semester, in November, of 2019/2020 school year. The method of this research was survey method with quantitative-causal approach and path analysis. The sample of this research were 98 student grade X MIPA. The instrument for knowledge about environmental issues is a true-false test, the instrument for intention to act and responsible environmental behavior is opinionary. Based of hypothesis test, there is no direct effect between knowledge about environmental issues toward responsible environmental behavior, and there is direct effect between knowledge about environmental issues toward intention to act and intention to act toward responsible environmental behavior. Based on these results, can be concluded that to develop responsible of environmental behavior, factors such as intention to act need to be considered, and in developing intention to act, factors such as knowledge about environmental issues need to be considered.
\end{abstract}

Keyword: intention to act, knowledge, path analysis, responsible environmental behavior, student. 


\section{PENDAHULUAN}

Seiring dengan berkembangnya era revolusi industri, semakin banyak perkembangan dalam berbagai bidang ilmu pengetahuan dalam bidang industri dan teknologi. Namun di balik perkembangan ilmu pengetahuan yang sangat pesat tersebut, semakin hari penurunan kualitas lingkungan semakin tak bisa dihindar. Perkembangan zaman selain membawa dampak positif bagi kehidupan manusia juga membawa dampak negatif saat manusia tidak bisa mengontrolnya (Zheng, 2017). Manusia tidak bisa dilepaskan dari lingkungannya. Dalam memenuhi kebutuhan hidupnya, manusia bukan hanya berkompetisi dengan manusia lain, namun juga dengan makhluk hidup lain seperti hewan dan tumbuhan dalam mendapatkan kebutuhan hidupnya (Chirras, 1999).

Perilaku manusia dalam memenuhi kebutuhan hidupnya, secara langsung maupun tidak langsung memiliki dampak bagi lingkungan (Putrawan, 2015). Untuk meminimalisir munculnya dampak negative dari usaha manusia dalam memenuhi kebutuhannya, maka diperlukan adanya perilaku bertanggung jawab lingkungan. Responsible environmental behavior atau pro-environmental behavior dapat didefiniskan sebagai perilaku-perilaku yang dilakukan untuk mengurangi atau meminimalisasi efek-efek negatif yang akan terjadi pada lingkungan (Kollmus dan Agyeman, 2002; Putrawan, 2015). Dari model perilaku yang dikemukakan oleh Hines, responsible environmental behavior muncul akibat adanya beberapa faktor, salah satunya adalah knowledge about environmental issues dan intention to act. 


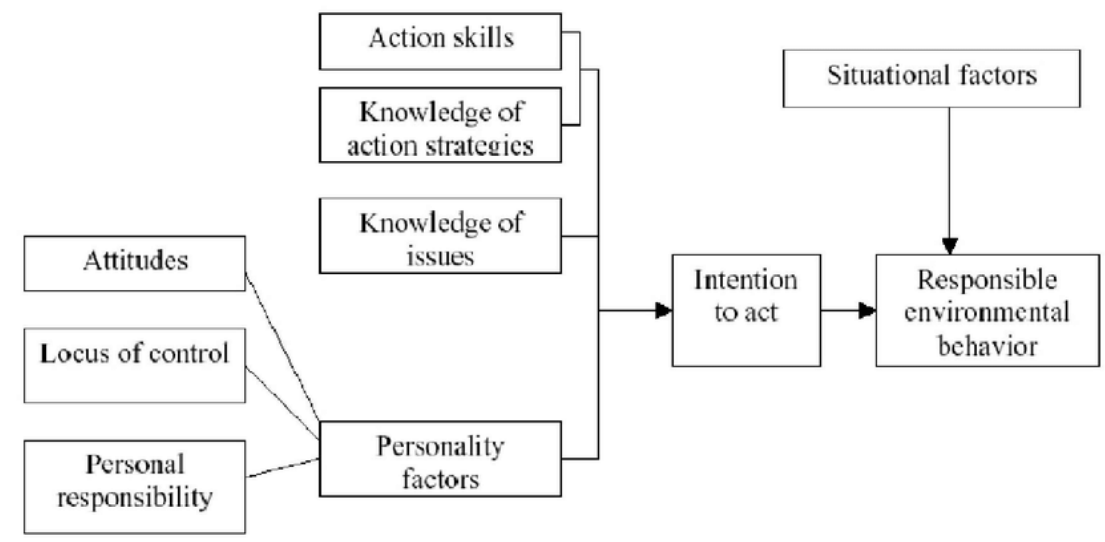

\section{Gambar 1. Model Perilaku yang Menggambarkan Pembentukan Responsible Environmental Behavior (Hines, 1987)}

Responsible environmental behavior seseorang dapat terlihat dari aktivitasaktivitasnya terhadap lingkungan. Seseorang dengan perilaku bertanggung jawab lingkungan akan seminim mungkin melakukan aktivitas yang merugikan lingkungan. Perilaku-perilaku tersebut dapat dilihat dari bagaimana seseorang mengolah sampahnya, menggunakan kemasan-kemasan yang tidak mencemari lingkungan, mendaur ulang sampah, dan kebijakan penggunaan listrik (Putrawan, 2017; Tanti dan Raya, 2016). Hines (1987) mengemukakan bahwa responsible environmental behavior terbentuk akibat dorongan dari faktor-faktor, diantaranya adanya knowledge about environmental issues dan intention to act.

Dari kamus Cambridge University, knowledge atau pengetahuan didefinisikan sebagai pemahaman terhadap sebuah informasi atau subjek yang didapatkan dari pengalaman atau proses pembelajaran. Environmental knowledge merujuk pada pemahaman seseorang terhadap lingkungan dan isu-isu yang berkaitan dengan lingkungan (Karen, 1988; Putrawan, 2015). Kollmus dan Agyeman (2002) mengungkapkan bahwa salah satu bagian dari environmental knowledge adalah knowledge about environmental issues atau pengetahuan terhadap isu-isu lingkungan. Knowledge about environmental issues dapat didefinisikan sebagai pada tingkat pemahaman seseorang terhadap masalah-masalah yang terjadi di lingkungannya. 
Pengetahuan memiliki sembilan dimensi, yaitu knowledge about specifics yang mencakup knowledge about terminology dan knowledge about specifics facts. Selanjutnya adalah dimensi knowledge about way and means with dealing specifics yaitu pengetahuan mengenai cara dan makna mengenai sesuatu hal. Dimensi ini mencakup knowledge about conventions, knowledge about trends and sequence, knowledge about classification and categories, knowledge about criteria, dan knowledge about methodology. Dimensi yang terakhir adalah knowledge about universal abstraction in fields atau pengetahuan mengenai hal-hal yang sifatnya universal atau abstrak (Bloom, 1956).

Pengetahuan mengenai lingkungan dan isu-isu yang terjadi pada lingkungan yang dimilikinya, akan membuat seseorang memiliki kepekaan lingkungan yang lebih tinggi, sehingga memunculkan keinginan untuk bertindak. Dengan adanya kepekaan lingkungan, akan muncul seseorang juga akan menjadi lebih antusias untuk melakukan aksi-aksi penyelamatan lingkungan agar isu-isu yang terjadi dapat terselesaikan (Putrawan, 2019).

Tai Yi Yu (2017) menyatakan bahwa pengetahuan seseorang mengenai sebuah hal akan mempengaruhi terbentuknya intensi untuk bertindak (intention to act) dalam diri orang tersebut. Salah satunya adalah pengetahuan mengenai lingkungan dan isu-isunya, akan mempengaruhi keinginan seseorang untuk melakukan hal yang dapat berkontribusi dalam upaya penyelamatan lingkungan. Intention to act adalah aktivitas yang dilakukan oleh seseorang, baik secara eksplisit maupun implisit yang dapat diukur dan diprediksikan (Zheng, 2017). Pengetahuan mengenai lingkungan akan menentukan bagaimana seseorang akan bertindak terhadap lingkungannya dengan munculnya keinginan-keinginan untuk melakukan sesuatu, yang kemudian akan diwujudkan melalui perilaku bertanggung jawab lingkungan (Putrawan, 2019). 


\section{METODOLOGI}

Metode yang digunakan dalam penelitian ini adalah metode survey yang bersifat kausal. Peneilitan ini merupakan jenis penelitian kuantitaif dengan teknik analisis jalur atau path analysis. Analisis jalur dilakukan untuk melihat pengaruh langsung dan pengaruh tidak langsung antara variabel eksogen dan variabel endogen. Dalam penelitian ini terdapat tiga variabel, yaitu X1 (knowledge about environmental issues) dan X2 (intention to act) sebagai variabel eksogen dan X3 (responsible environmental behavior) sebagai variabel endogen. Model hipotetik dari penelitian ini dapat digambarkan sebagai berikut:

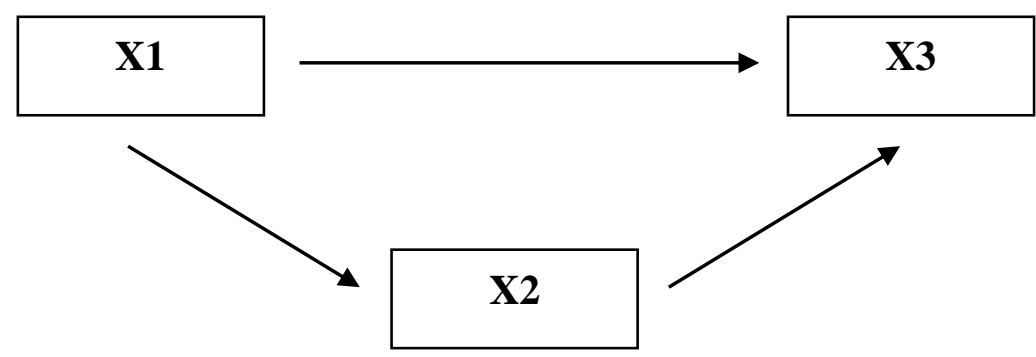

\section{Gambar 2. Model Hipotetik Penelitian}

Populasi dari penelitian ini adalah seluruh siswa SMA kelas X MIPA di provinsi Jawa Barat. Penentuan sampel penilitan dilakukan dengan teknik multistage random sampling. Pertama, dipilih populasi penelitian yang akan diteliti adalah seluruh siswa SMA Negeri kelas $\mathrm{X}$ MIPA di Jawa Barat. Kedua, dengan menggunakan teknik purposive sampling dipilih SMA Negeri di Kota Bekasi dari seluruh SMA Negeri di Jawa Barat. Ketiga, dengan menggunakan cluster random sampling terpilih SMA Negeri di Kecamatan Bekasi Utara, dari dua belas kecamatan yang ada di Kota Bekasi. Keempat, terpilih SMA Negeri 4 Kota Bekasi dengan cluster random sampling. Dari seluruh kelas X MIPA di SMA Negeri 4 Kota Bekasi, dipilih 3 kelas sebagai responden. Kemudian, mengunakan teknik Simple Random Sampling dari tiga kelas dengan jumlah 105 siswa terpilih sampel sebanyak 
98 siswa. Selanjutnya, sampel diuji dengan rumus McClave dan didapat standar eror sebesar 0.9 yang menunjukkan bahwa data sampel homogen dan representatif.

\section{HASIL DAN PEMBAHASAN}

Hipotesis penelitian diuji menggunakan uji $\mathrm{F}$ dengan hasil sebagai berikut:

a) Pengaruh Langsung Knowledge about Environmental Issues (X1) terhadap

\section{Responsible Environmental Behavior (X3)}

Dari data hasil perhitungan untuk penyusunan model persamaan regresi knowledge about environmental issues (X1) atas responsible environmental behavior (X3) diperoleh konstanta regresi $\mathrm{a}=76,202$ dan koefisien regresi $\mathrm{b}=0$, 139. Dengan demikian hubungan model persamaan regresi sederhana adalah $\hat{X}_{3}$ $=76,02+0,139 \mathrm{X}_{1}$. Sebelum model persamaan regresi dianalisis lebih lanjut, terlebih dahulu dilakukan uji signifikansi dan linearitas persamaan model regresi.

Pengujian signifikansi regresi menggunakan uji ANAVA regresi dari setiap variabel yang diukut. Hasil pengujian regresi signifikansi knowledge about environmental issues (X1) terhadap responsible environmental behavior (X3) diperoleh $F_{\text {hitung }}$ sebesar 0,133 sedangkan $F_{\text {tabel }}$ sebesar 2,75 sehingga $F_{\text {hitung }}<$ $\mathrm{F}_{\text {tabel. }}$ Dari hasil tersebut, dinyatakan bahwa persamaan regresi $\hat{\mathrm{X}}_{3}=76,02+$ $0,139 \mathrm{X}_{1}$ adalah tidak signifikan.

\section{b) Pengaruh Langsung Knowledge about Environmental Issues (X1) terhadap Intention to Act (X2)}

Dari data hasil perhitungan untuk penyusunan model persamaan regresi knowledge about environmental issues (X1) atas intention to act (X2) diperoleh konstanta regresi $a=85,016$ dan koefisien regresi $b=1,097$. Dengan demikian hubungan model persamaan regresi sederhana adalah $\hat{X}_{2}=85,016+1,097 \mathrm{X}_{1}$. Sebelum model persamaan regresi dianalisis lebih lanjut, terlebih dahulu dilakukan uji signifikansi dan linearitas persamaan model regresi. 
Pengujian signifikansi regresi menggunakan uji ANAVA regresi dari setiap variabel yang diukur. Untuk pengujian signifikansi regresi diperoleh $F_{\text {hitung }}$ sebesar 4,093 sedangkan $F_{\text {tabel }}$ sebesar 3,94 sehingga $F_{\text {hitung }}>F_{\text {tabel }}$. Maka persamaan regresi $\hat{X}_{2}=$ $85,016+1,097 \mathrm{X}_{1}$ adalah signifikan. Selanjutnya, pengujian linearitas regresi knowledge about environmental issues (X1) terhadap intention to act (X2). Hasil

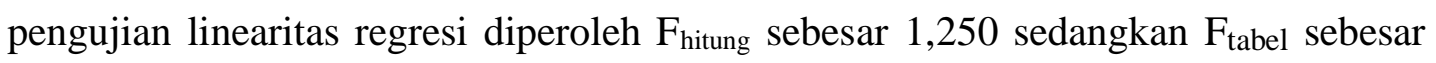
1,945 sehingga $F_{\text {hitung }}<F_{\text {tabel }}$. Sehingga dikatakan persamaan regresi $\hat{X}_{2}=85,016+$ $1,097 \mathrm{X}_{1}$ adalah linier.

Pengujian koefisien jalur X1 terhadap X2 dapat dilihat pada tabel berikut:

Tabel 1. Tabel Koefisien Korelasi dan Koefisien Jalur X1 terhadap X2

\begin{tabular}{|c|c|c|c|c|c|c|c|}
\hline \multirow[t]{2}{*}{ Model } & \multicolumn{2}{|c|}{$\begin{array}{c}\text { Unstandardized } \\
\text { Coefficients }\end{array}$} & \multirow{2}{*}{$\begin{array}{l}\text { Standardized } \\
\text { Coefficients }\end{array}$} & \multirow[t]{2}{*}{$\mathrm{t}$} & \multirow[t]{2}{*}{$\begin{array}{l}t \text { tabel } \\
(0,05)\end{array}$} & \multicolumn{2}{|c|}{ Correlations } \\
\hline & $\mathrm{B}$ & $\begin{array}{l}\text { Std. } \\
\text { Error }\end{array}$ & & & & $\begin{array}{ll}\text { Zero- } & \text { Partial } \\
\text { order } & \end{array}$ & Part \\
\hline (Constant) & 85.016 & 11.711 & & 7.259 & & & \\
\hline $\mathrm{X} 1$ & 1.097 & .542 & .202 & $2.023^{*}$ & 1,98 & .202 & 202 \\
\hline
\end{tabular}

a. Dependent Variable: X2

Karena $t_{\text {hitung }}>t_{\text {tabel }}$ yaitu $2,023>1,98$ sehingga tolak $\mathrm{H} 0$ pada $(\alpha)=0,05$, yang berarti koefisien korelasi signifikan.

\section{c) Pengaruh Langsung Intention to Act (X2) terhadap Responsible}

\section{Environmental Behavior (X3)}

Dari data hasil perhitungan untuk penyusunan model persamaan regresi intention to act (X2) atas responsible environmental behavior (X3) diperoleh konstanta regresi $\mathrm{a}=34,383$ dan koefisien regresi $\mathrm{b}=0,413$. Dengan demikian hubungan model persamaan regresi sederhana adalah $\hat{\mathrm{X}}_{3}=34,383+0,413 \mathrm{X}_{2}$.Sebelum model persamaan regresi dianalisis lebih lanjut, terlebih dahulu dilakukan uji signifikansi dan linearitas persamaan model regresi.

Pengujian signifikansi regresi menggunakan uji ANAVA regresi dari setiap variabel yang diukur. Hasil dari pengujian signifikansi regresi diperoleh $F_{\text {hitung }}$ sebesar 53,906 sedangkan $F_{\text {tabel }}$ sebesar 6,906 sehingga $F_{\text {hitung }}>F_{\text {tabel. }}$. Maka 
dinyatakan bahwa persamaan regresi $\hat{\mathrm{X}}_{3}=34,383+0,413 \mathrm{X}_{2}$ adalah sangat signifikan. Selanjutnya dilakukan pengujian linearitas menggunakan uji ANAVA regresi dari setiap variabel yang diukur. Hasil pengujian linearitas regresi intention to act (X2) atas responsible environmental behavior (X3). Hasil pengujian linearitas regresi diperoleh $F_{\text {hitung }}$ sebesar 0,965 sedangkan $F_{\text {tabel }}$ sebesar 1,61 sehingga $F_{\text {hitung }}<\mathrm{F}_{\text {tabel. }}$ Maka persamaan regresi $\hat{X}_{3}=34,383+$ $0,413 \mathrm{X}_{2}$ adalah linier. Pengujian koefisien korelasi dan koefisien jalur menggunakan uji Pearson Product Moment dari setiap variabel yang diukur. Hasil perhitungan koefisien korelasi X2 terhadap X3 dapat dilihat pada tabel berikut:

Tabel 2. Koefisien Korelasi dan Koefisien Jalur X2 terhadap X3

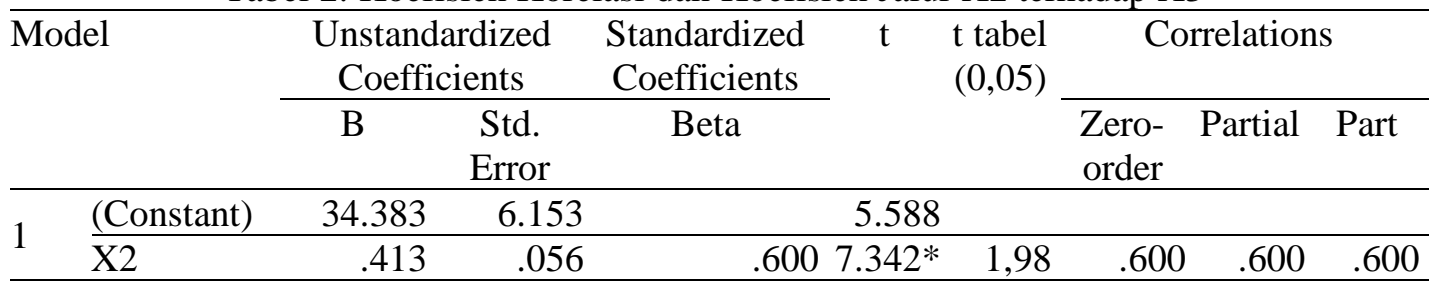

a. Dependent Variable: X3

Karena $t_{\text {hitung }}>\mathrm{t}_{\text {tabel }}$ yaitu 7,342 $>1,98$ sehingga tolak $\mathrm{H} 0$ pada $(\alpha)=0,05$, yang berarti koefisien korelasi signifikan.

\section{d) Pengaruh Tidak Langsung Knowledge about Environmental Issues (X1)} terhadap Responsible Environmental Behavior (X3) melalui Intention to Act (X2)

Pengaruh variabel knowledge about environmental issues terhadap variabel responsible environmental behavior melalui variabel intention to act dapat diperoleh denganmenggunakan rumus sebagai berikut :

Phi31.2 = (Phi21) $($ Phi32). Hasil perhitungan menunjukkan bahwa thitung 1,344< $\mathrm{t}_{\text {tabel }}(0,01 ; 95)=2,628$, yang artinya tidak terdapat pengaruh tidak langsung X1 terhadap X3 melalui X2. Dengan hasil demikian dapat disimpulkan bahwa intention to act bukan merupakan variabel mediasi yang baik antara knowledge about environmental issues terhadap responsible environmental issues. 
Tabel 3. Rangkuman Hasil Pengujian Hipotesis

\begin{tabular}{lccc}
\hline Hipotesis Statistika & Koefisien Jalur & t hitung & t tabel \\
\hline $\mathrm{H}_{0}: \mathrm{Phi}_{31}=0$ & - & - & - \\
$\mathrm{H}_{1}: \mathrm{Phi}_{31}>0$ & & 2,023 & 1,98 \\
\hline $\mathrm{H}_{0}: \mathrm{Phi}_{21}=0$ & 0,202 & & \\
$\mathrm{H}_{1}: \mathrm{Phi}_{21}>0$ & & 7,342 & 2,628 \\
\hline $\mathrm{H}_{0}: \mathrm{Phi}_{32}=0$ & 0,6 & & 2,628 \\
$\mathrm{H}_{1}: \mathrm{Phi}_{32}>0$ & & 1,344 & \\
\hline $\mathrm{H}_{0}: \mathrm{Phi}_{32}=0$ & 0,1212 & & \\
$\mathrm{H}_{1}: \mathrm{Phi}_{32}>0$ & & & \\
\hline
\end{tabular}

Dari hasil-hasil pengujian hipotesis, maka model empirik dari hasil penelitian ini dapat digambarkan sebagai berikut:

$0,037^{\text {ns }}$

$(0,037)$

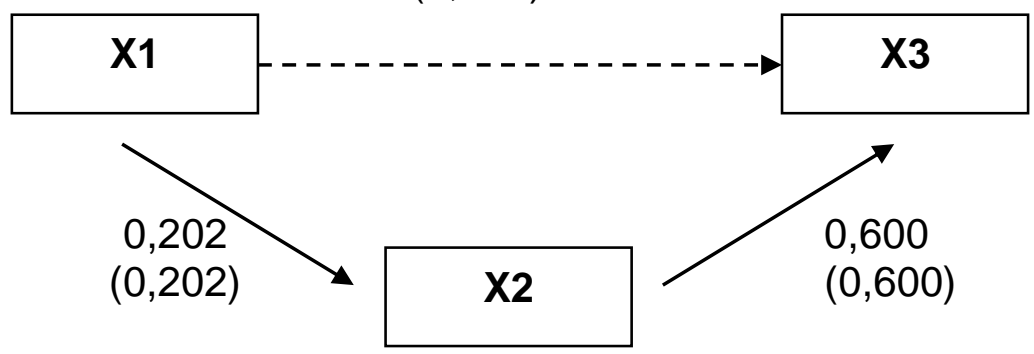

Gambar 3. Hasil Akhir Model Empirik Penelitian

${ }^{*} \mathrm{p}, 0,05 ; * * \mathrm{p}<0,01 ;{ }^{\mathrm{ns}}:$ tidak signifikan

Keterangan:

X1: Knowledge about Environmental Issues

$\mathrm{X} 2$ : Intention to Act

X3: Responsible Environmental Behavior 
Berdasarkan hasil pengujian hipotesis, dapat diketahui bahwa knowledge about environmental issues dapat mempengaruhi intention to act siswa dan intention to act dapat mempengaruhi responsible environmental behavior siswa. Namun, tidak terdapat pengaruh langsung antara knowledge about environmental issues terhadap responsible environmental behavior siswa, dan intention to act bukan merupakan variabel mediator yang baik antara knowledge about environmental issues terhadap responsible environmental behavior siswa.

Terdapat perbedaan hasil antara pengujian hipotesis pengaruh langsung antara knowledge about environmental issues terhadap responsible environmental behavior siswa pada penelitian ini dengan penelitian sebelumnya. Ketika seseorang memiliki knowledge about environmental issues yang tinggi, maka responsible environmental behaviornya juga tinggi karena ia akan cenderung lebih peduli terhadap lingkungannya (Mary dan Richard, 2016; Putrawan, 2019). Namun, hal tersebut tidak ditemukan dalam hasil penelitian ini. Perbedaan hasil ini dapat terjadi karena adanya faktor-faktor lain yang mempengaruhi, diantaranya personality dan attitude yang dimiliki oleh seseorang.

Di Indonesia, telah terjadi peningkatan environmental awareness yang cukup baik. Masyarakat mulai peka mengenai pentingnya menghemat energi yang terlihat dari tingginya antusiasme setiap pelaksaan Earth Hour. Penggunaan transportasi umum juga meningkat, yang menunjukkan adanya penurunan penggunaan kendaraan pribadi. Pembelian produk-produk ramah lingkungan juga mengalami peningkatan. Hal-hal tersebut menunjukkan adanya peningkatan dalam perilaku bertanggungjawab lingkungan yang dimiliki masyarakat Indonesia.

Hasil pengujian hipotesis pengaruh langsung antara knowledge about environmental issues terhadap intention to act, dan intention to act dapat mempengaruhi responsible environmental behavior siswa didapatkan sesuai dengan teori. Hasil penelitian yang didapatkan telah sesuai dengan model teori yang dikemukakan oleh Hines, dimana environmental knowledge, bersama personality dan attitude merupakan faktor-faktor yang mempengaruhi intention to act seseorang. 
Perilaku bertanggung jawab lingkungan merupakan perilaku seseorang yang memiliki efek terhadap lingkungannya (Putrawan, 2019). Perilaku ini dapat timbul akibat munculnya keinginan untuk bertindak dalam diri individu (Putrawan, 2019). Hasil penelitian ini sesuai dengan penelitian lain yang sudah dilakukan sebelumnya. Salah satu penelitian relevan adalah penelitian yang dilakukan oleh Tanti Handriana pada tahun 2016. Hasil dari penelitian tersebut menunjukkan bahwa terdapat hubungan antara intention to act yang dimiliki seseorang dengan perilakunya terhadap lingkungan.

Uji hipotesis yang terakhir menunjukkan bahwa intention to act bukan merupakan variabel mediator yang baik antara knowledge about environmental issues dan responsible environmental behavior siswa. Hasil penelitian yang didapatkan tidak sesuai dengan penelitian relevan yang telah dilakukan sebelumnya. Min Seong Kim pada tahun 2018 yang menunjukkan bahwa environmental knowledge memiliki pengaruh terhadap environmental behavior melalui intention to act.

Namun, penelitian yang dilakukan Ferdinando mengemukakan hasil bahwa intention to act tidak selalu menjadi variabel mediator yang baik antara knowledge dan responsible environmental behavior. Hal ini karena, ada hal lain yang mempengaruhi terbentuknya keinginan seseorang untuk bertindak, yaitu situasi budaya dan masyarakat di tempat tinggal seseorang tersebut. kebiasaan-kebiasaan yang dimiliki oleh suatu kelompok masyarakat dapat mempengaruhi bagaimana respon seseorang terhadap hal yang terjadi di sekelilingnya dan bagaimana ia memproses pengetahuan yang dimilikinya menjadi sebuah intensi untuk bertindak yang akan direalisasikan melalui perilaku kesehariannya. 


\section{KESIMPULAN}

Temuan-temuan yang didapat dari hasil penelitian antara lain:

1) Knowledge about environmental issues tidak berpengaruh langsung terhadap responsible environmental behavior siswa.

2) Knowledge about environmental issues berpengaruh langsung terhadap intention to act siswa.

3) Intention to act berpengaruh langsung terhadap responsible environmental behavior siswa.

4) Intention to act bukan merupakan variabel mediator yang baik antara knowledge about environmental issues terhadap responsible environmental behavior siswa.

Berdasarkan temuan-temuan tersebut, maka dapat disimpulkan bahwa knowledge about environmental issues yang dimiliki siswa berpengaruh responsible environmental behavior siswa secara langsung maupun melalui intention to act. Intention to act bukan variabel mediator yang baik antara knowledge about environmental issues dan responsible environmental behavior siswa. Dalam membentuk responsible environmental behavir, maka perlu dipertimbangakan faktor-faktor seperti knowledge about environmental issues dan intention to act siswa.

\section{REFERENSI}

Bloom, Benjamin S. (1956) Taxonomy about Educational Objectives: The Classification about Educational Goals. United States of America: David Mc.Kay Company.

Chiras, Daniel D. (1999) Human Biology. Massachusetts: Jones and Bartlett Publishers

Fornara, Ferdinando., et.al. (2011) "Distinguishing the sources of normative influence on proenvironmental behaviors: The role of local norms in household waste recycling" Group Processes \& Intergroup Relations. 14 (5). 623-635 
Handriana, Tanti., Ambara, Raya. (2016) "Responsible Environmental Behavior Intention of Travelers on Ecotourism Sites", Tourism and Hospitality Management. 22(2). 135-150

Hayward, Karen. (1988) Responsible Environmental Behaviour: A Test about the Hines Mode [Thesis]. Canada: York University.

Hines, et al. (1987) "Analysis and Synthesis of Research on Responsible Environmental Behavior: A Meta Analysis." The Journal about Environmental Education. 18. 1-8.

Kollmus, Anja., Agyeman, Julian. (2002) "Mind the Gap: Why Do People Act Environmentally and What Are The Barriers to Pro-Environmental Behavior?" Environmental Education Research. 8(3). 239-260

Latif, Saripah Abdul., dkk. (2013) "Role of Environmental Knowledge in Creating Pro-Environmental Residents", Procedia-Social and Behavioral Science. 105. $866-874$

Pothitou, Mary., Hanna, Richard. (2016) "Environmental Knowledge, ProEnvironmental Behaviour and Energy Savings in Households: An Empirical Study." Technology for Sustainable Built Environment Center. 1-20

Putrawan, I Made. (2017) 'Predicting Students' Responsible Environmental Behavior (REB) Based on Personality, Students' New Environmental Paradigm (NEP) and Naturalistic Intelligence" American Scientific Publishers. 23(9) .8586-8593

Putrawan, I Made. (2015) "Measuring New Environmental Paradigm Based on Students' Knowledge About Ecosystem and Locus of Control" Eurasia Journal of Mathematics, Science \& Technology. 11(2). 325-333

Putrawan, I Made. (2019) "Environment and Commitment, Locus of Control and Intention to Act" Indian Journal of Public Health Research and Development. 10(9).1781-1785

Putrawan, I Made. (2019) 'Pro-Environmental Behavior (PEB) and Its' Related Factors' Construct Validity" Journal of Adv Research in Dynamical \& Control System. 11(9). 362-370

Putrawan, I Made. (2019) “A Comparative Analysis of New Ecological Paradigm (NEP), Ecosystem Knowledge, and Stduents' Self-Control Based on Gender" International Journal of Innovative Technology and Exploring Engineering. 8. 68-71 
Putrawan, I Made. (2019) "The Effect of Personal Commitment and Personam Investment, Intention to Act on Students' Citizenship Behavior" International Journal of Recent Technology and Engineering. 7. 803-807

Putrawan, I Made. (2019) "The Effect of Instructional Leadersgip and Naturalistic Intelligence on Students Citizenship Behavior toward Environment Mediated by Environmental Moral/Ethic" Journal of Adv Research in Dynamical \& Control System. 11(9). 87-92

Yu, Tai Yi., Yu, Tai Kuei. (2017) “The Moderating Effects of Students' Personality Traits on Pro-Environmental Behavioral Intention Respons to Climate Change." International Journal about Environmental Research and Public Health. 14. 1-20

Zheng, Q.J., dkk. (2017) "Correlation Between the Environmental Knowledge, Environmental Attitude, and Behavioral Intention of Tourists for Ecotourism in China." Applied Biology and Environmental Research. 16(1). 51-62

Www.cambridge.dictionary.org. Diakses pada 20 Juli 2019 pukul 22:00 WIB. 